\title{
Starvation stress attenuates the miRNA- target interaction in suppressing breast cancer cell proliferation
}

Jinhui Lü ${ }^{1+}$, Chuyi Zhang ${ }^{1+}$, Junyi Han ${ }^{2 \dagger}$, Zhen Xu', Yuan Li', Lixiao Zhen ${ }^{1}$, Qian Zhao ${ }^{1}$, Yuefan Guo ${ }^{1}$, Zhaohui Wang ${ }^{1,3}$, Evelyne Bischof ${ }^{4,5^{*}}$ and Zuoren $\mathrm{Yu}^{1^{*}}$ (i)

\begin{abstract}
Background: Emerging evidence has demonstrated the limited access to metabolic substrates as an effective approach to block cancer cell growth. The mechanisms remain unclear. Our previous work has revealed that miR221/222 plays important role in regulating breast cancer development and progression through interaction with target gene p27.

Results: Herein, we determined the miRNA-mRNA interaction in breast cancer cells under induced stress status of starvation. Starvation stimulation attenuated the miR-221/222-p27 interaction in MDA-MB-231 cells, thereby increased p27 expression and suppressed cell proliferation. Through overexpression or knockdown of miR-221/222, we found that starvation-induced stress attenuated the negative regulation of p27 expression by miR-221/222. Similar patterns for miRNA-target mRNA interaction were observed between miR-17-5p and CyclinD1, and between mR-155 and Socs1. Expression of Ago2, one of the key components of RNA-induced silencing complex (RISC), was decreased under starvation-induced stress status, which took responsibility for the impaired miRNA-target interaction since addition of exogenous Ago2 into MDA-MB-231 cells restored the miR-221/222-p27 interaction in starvation condition.

Conclusions: We demonstrated the attenuated interaction between miR-221/222 and p27 by starvation-induced stress in MDA-MB-231 breast cancer cells. The findings add a new page to the general knowledge of negative regulation of gene expression by miRNAs, also demonstrate a novel mechanism through which limited access to nutrients suppresses cancer cell proliferation. These insights provide a basis for development of novel therapeutic options for breast cancer.
\end{abstract}

Keywords: Breast cancer, Starvation, miRNA, Target interaction, Proliferation

\footnotetext{
* Correspondence: ewelinabiskup@yahoo.de; zuoren.yu@tongji.edu.cn

†Jinhui Lü, Chuyi Zhang and Junyi Han contributed equally to this work.

${ }^{4}$ Shanghai University of Medicine and Health Sciences Clinical Medicine Division, Shanghai, China

${ }^{1}$ Research Center for Translational Medicine, Tongji University School of Medicine, 150 Jimo Road, Shanghai 200120, China

Full list of author information is available at the end of the article
}

(c) The Author(s). 2020 Open Access This article is licensed under a Creative Commons Attribution 4.0 International License, which permits use, sharing, adaptation, distribution and reproduction in any medium or format, as long as you give appropriate credit to the original author(s) and the source, provide a link to the Creative Commons licence, and indicate if changes were made. The images or other third party material in this article are included in the article's Creative Commons licence, unless indicated otherwise in a credit line to the material. If material is not included in the article's Creative Commons licence and your intended use is not permitted by statutory regulation or exceeds the permitted use, you will need to obtain permission directly from the copyright holder. To view a copy of this licence, visit http://creativecommons.org/licenses/by/4.0/ The Creative Commons Public Domain Dedication waiver (http://creativecommons.org/publicdomain/zero/1.0/) applies to the data made available in this article, unless otherwise stated in a credit line to the data. 


\section{Background}

Breast cancer is still one of the most prevalent neoplasms globally, with a persistently high prevalence despite numerous diagnostic progresses and prevention measures. The mortality is still significant, despite a slight decline in the last two decades. Old age is the most important risk factor for breast cancer, which explains the persistently increasing incidence, especially in developed countries [1-3].

Breast cancer is one of the most heterogenous diseases. Albeit there is a number of established predictive and prognostic factors, most of which are also therapeutic targets (e.g. estrogen, progesterone receptor (ER, PR) or HER-2), the management options are still primarily based on the cancer's basic clinicopathological features, such as tumor size, lymph node stage, histological grade, type, and lymphovascular invasion [4-7]. Especially, the oldest old cancer patients are being excluded from various therapeutic options due to their frailty and vulnerability towards anticancer-therapy-related side effects [8-10]. Increasingly, discoveries in breast cancer genomics, proteomics and lipidomics are opening our understanding and categorizations [11-13]. However, these analyses are relatively expensive and remain mostly in the theoretical frame. Therefore, there is an urgent need for new indicators and approaches in personalized therapies, offering targeted care with minimal toxicities.

While caloric restrictions in humans showed positive clinical influence on various neurocognitive disorders (NCD) and aging, fasting in cancer patients is controversially debated, especially due to potential increase of tumor growth due to reactive increase of growth factors after fasting cessation, hyperglycemia and hyperinsulinemia, but no valid and reliable trials were conducted so far. Emerging evidence showed starving tumor cells of nutrients are capable to stop cancer cell growing [14]. The constitutive anabolism of cancer cells not only supports proliferation but also addicts tumor cells to a steady influx of exogenous nutrients. Limiting access to metabolic substrates is effective to block cancer growth [15]. Recent reports from animal models illustrated positive relations between starvation and cancer, such as better outcomes in mice after 2-3 fasting days prior to chemotherapy [16-18]. Related hypotheses suggest that fasting renders tumor cells susceptible towards chemotherapy due to a differential stress resistance: since tumor cells are supposedly less adaptable to acute environmental changes, they become hyperactive and hypermitotic under starvation [19]. Such processes lead to chromosomal damage, DNA- and cellular instability, thus a higher sensitivity to chemo- or radio- therapy, despite the fact that paradoxically, these pathophysiologic processes are also causative of tumor growth and progression $[20,21]$.
Therefore, our study aimed to elaborate on the underlying molecular mechanisms of how fasting links to shrinkage of solid tumors and whether these findings can be translated to humans, using miRNAs (microRNAs) as crucial players in tumorigenesis and progression. miRNAs become severely deregulated during cancerous processes, which impairs their main function on targeted genes by degradation of mRNA or inhibition of mRNA translation. Recently, miRNA-mRNA interactions have been described in the context of signature interactions within well-established cancer pathways, e.g. in breast and pancreatic cancer [22-24]. Nevertheless, some studies revealed that miRNAs have the capability of activating gene expression directly or indirectly in respond to different cell types and cell conditions [24, 25]. However, it is thus far unclear whether miRNA-mRNA interactions depend on the cell status, such as stress induced by external conditions (e.g. starvation). Establishing such correlation would allow for new therapeutic options.

In our previous research, we showed that miR-221/222 is a potential oncogenic gene in breast cancer, and validated target genes p27 downstream of miR-221/222 [26]. The expression levels of miR-221/222 are upregulated in breast cancer, especially in basal-like breast cancer subtype. For example, miR-221/222 showed 20-40 times higher in expression in MDA-MB-231 cell, compared to luminal breast cancer cell types [26]. Targeted knockdown of miR-221 and/or miR-222 suppressed cell proliferation and promoted the cell sensitivity to chemotherapy in human breast cancer [26]. Herein we found that the interaction between miR-221/222 and p27 is dependent on the cell status in human breast cancer cells. Starvation-induced stress showed influence of miRNA-mRNA interaction.

\section{Methods}

\section{Cell lines and culture}

Human breast cancer cell lines MCF-7 and MDA-MB-231 were originally obtained from American Type Culture Collection (ATCC), and maintained in our laboratory. The two cell lines were not included in the list of contaminated cell lines (http://en.wikipedia.org/wiki/List_of_contaminated_cell_lines). Cells are free of mycoplasma contamination according to a recent test in our lab. Cells were regularly cultured in DMEM containing glucose (4.5 $\mathrm{g} / \mathrm{L})$, penicillin and streptomycin (100 $\mathrm{mg}$ of each/L), supplemented with $10 \%$ fetal bovine serum (FBS). Starvation cell culture condition included DMEM containing glucose $(1.0 \mathrm{~g} / \mathrm{L})$, penicillin and streptomycin $(100 \mathrm{mg}$ of each/L) and supplementation with only $0.1 \%$ FBS.

\section{Oligos, plasmid and transfection}

Anti-miR-221 (5' gaaacccagcagacaauguagcu 3'), antimiR-222 (5' acccaguagccagauguagcu $3^{\prime}$ ), anti-miR-NC scramble (5' guguaacacgucuauacgccca $\left.3^{\prime}\right)$, miR-17-5p 
(5' caaagugcuuacagugcagguag $\left.3^{\prime}\right)$, miR-155 (5' uuaaugcuaaucgugauagggguu $3^{\prime}$ ) and miR-NC scramble (5' agucgcauaccucgacaauaau $3^{\prime}$ ) oligos were designed following LNA Oligo Tools and Design Guidelines of Exiqon (Vedbaek, Denmark), and synthesized per GenScript (Nanjing, China). siRNA to Ago2 and negative control were purchased from Guangzhou RiboBio Co., Ltd. (Guangzhou, China). The HiPerFect transfection reagent from Qiagen (Venlo, The Netherland) was used for RNA oligos cell transfection according to the manufacturer's instructions. Final RNA oligo concentrations of $50 \mathrm{nM}$ were used for all in vitro assays. miR-221 and miR-222 expression vectors, as previously described in the literature [27], were provided by Moffitt Cancer Center \& Research Institute. pcDNA3.1-Ago2 plasmid was presented by Dr. Yandong Li from Tongji University. Lipofectamine 2000 (Invitrogen, USA) was used for plasmid transfections, following the manufacturer's instructions. Sequences for all primers are available upon request.

\section{Cell proliferation assays}

For the 3-(4,5-dimethylthiazol-2-yl)-2,5 -diphenyltetrazolium (MTT) assay, $4 \times 10^{3}$ cells/well were seeded into 96-well plate in triplicates. After culturing for 24 and 48 $\mathrm{h}$, cells were stained with MTT solution for $3 \mathrm{~h}$ under cell-culturing conditions, followed by dissolving with DMSO. The cell growth was determined by measuring OD value at $570 \mathrm{~nm}$ wavelength.

\section{Western blot}

Cell lysates $(50 \mu \mathrm{g})$ were separated by $10 \%$ SDS/PAGE. The proteins were transferred to nitrocellulose membrane. After being blocked in 5\% milk (w/v) at room temperature for $1 \mathrm{~h}$, the membranes were incubated at $4{ }^{\circ} \mathrm{C}$ overnight with primary antibodies (1:1000). Following $1 \times$ PBST washing, the membranes were incubated with secondary antibodies (1:3000) at room temperature for $1 \mathrm{~h}$ followed by ECL staining. The following antibodies were applied: anti-p27 (sc-776, Santa Cruz), anti-Cyclin D1 (sc-20,044, Santa Cruz), anti-E2F1 (sc-251, Santa Cruz), anti-Ago2 (04-642, Millipore), anti-Socs1 (ab62584, Abcam) and anti- $\beta$-actin (sc-47778, Santa Cruz).

\section{Luciferase reporter assay}

pGL3-p27 3'UTR vector, carrying the whole 3'UTR sequence of human p27 mRNA, was prepared as described in the literature [26]. $293 \mathrm{~T}$ cells were seeded on 12-well plates at a density of $1 \times 10^{5}$ cells/well in an antibioticfree medium for $24 \mathrm{~h}$ under regular or starvation conditions. $24 \mathrm{~h}$ later, $1.0 \mu \mathrm{g} /$ well of pGL3-p27 3'UTR, $0.2 \mu \mathrm{g} /$ well of Renilla plasmid and anti-miRNA (50 nM) were co-transfected using HiPerFect transfection reagent from Qiagen (Venlo, The Netherland). For the following $18 \mathrm{~h}$, luciferase activities were measured using Dual-Luciferase Reporter Assay System (Promega) by AutoLumat.

\section{Statistical analysis}

The standard two-tailed student's $t$-test was used for statistical analysis, in which $p<0.05$ was considered statistically significant. Data are presented as mean \pm SEM.

\section{Results}

Starvation condition suppressed cell proliferation in MDAMB-231 breast cancer cells

In order to determine the influence of the cell proliferation and gene expression by starvation stimulation, MTT assays were conducted in MDA-MB-231 cells under culturing condition of starvation. We observed a significant inhibition of cell proliferation (Fig. 1a). Western blot analysis demonstrated increase of p27 (Fig. 1b) and decrease of Cyclin D1 (Fig. 1c) in expression under starvation condition.

Starvation-induced stress attenuated the miR-221/222p27 interaction in MDA-MB-231 breast cancer cells miRNA has been well defined to interact with target mRNA through seed sequence complementarity. miR$221 / 222$ has two binding sites within the 3'UTR sequence of target gene p27, which is highly conserved between human and rodents (Fig. 2a-c). Adding miRNA inhibitors to MDA-MB-231 led to a suppression of cell proliferation by both anti-miR-221 and anti-miR-222 (Fig. 2d), which were attenuated by starvation stimulation (Supplemental Fig. S1). miR-221/222 were knocked down or overexpressed in MDA-MB-231 cells, followed by western blot analysis and quantitative real-time PCR to detect the p27 expression at both protein and mRNA levels. As shown in Fig. 2e and Supplemental Fig. S2, p27 expression was significantly upregulated after inhibition of miR-221 and/or miR-222 under regular culture condition, while this upregulation was not seen when the cells were cultured under starvation condition. In consistence, overexpression of miR-221 and/or miR-222 significantly downregulated the expression of p27 under regular condition, but not under starvation condition (Fig. 2f and Supplemental Fig. S3).

In order to further analyze the miRNA-mRNA interaction in cells at starvation-induced stress, a luciferase reporter vector carrying 3'UTR of p27 containing two binding sites to miR-221/222 (Fig. 3a) was transfected into cells. As shown in Fig. 3b, knockdowns of miR-221 and/or miR-222 upregulated the luciferase activity to over 3 -fold through interaction with p27 3'UTR under normal cell culture condition. However, the luciferase activity did not show influence by antimiR221/222 under starvation condition (Fig. 3c), which is consistent with the results in Fig. 2. The expression status of the immediate downstream and associating genes of $\mathrm{p} 27$, 
A

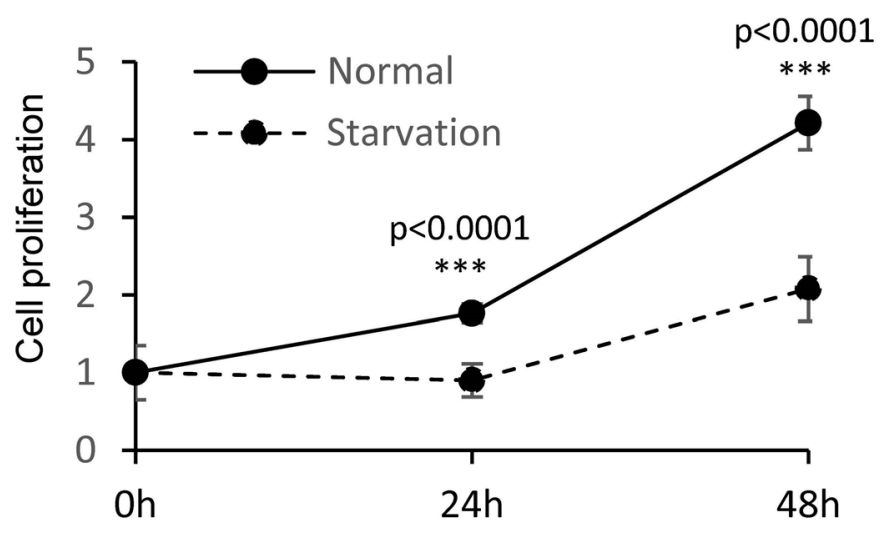

B
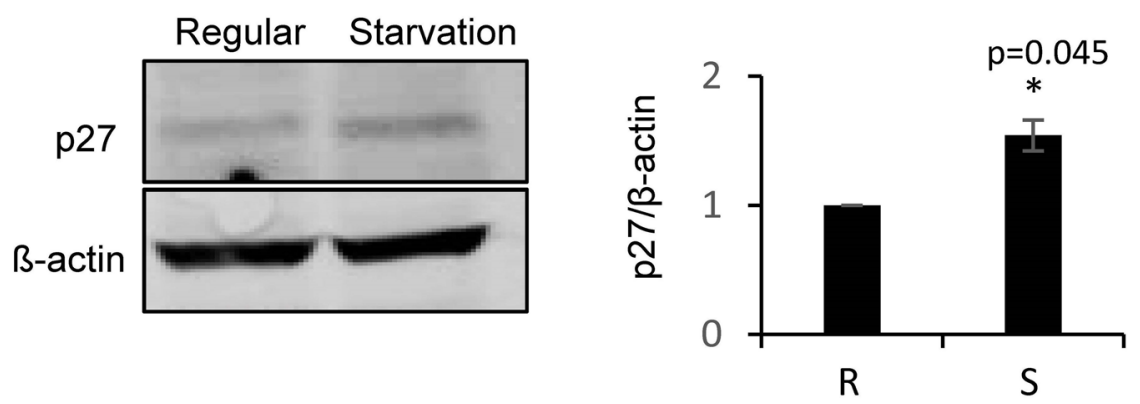

C
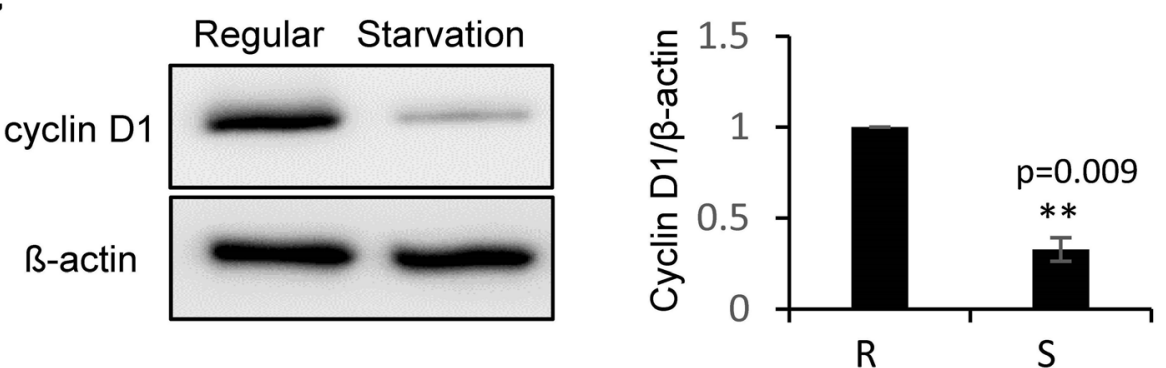

Fig. 1 Starvation stimulation suppressed cell proliferation in human breast cancer. a: MTT assays showing decreased cell proliferation of MDA-MB-231 cells by starvation stimulation, compared to regular cell culture condition. $\mathbf{b}$ : Western blot analysis demonstrating the increased p27 expression by starvation stimulation in MDA-MB-231 cells. c: Western blot analysis demonstrating the decreased Cyclin D1 expression under starvation in MDA-MB-231 cells. $\beta$-actin served as loading control. Original gels for western blots were shown in Supplemental Fig. S6. Data are derived from three independent analyses, and presented as mean \pm SEM $(n=3) .{ }^{*} p<0.05,{ }^{* *} p<0.01,{ }^{* * *} p<0.0001$

such as E2F1 and Cyclin D1, was further analyzed under normal and starvation status with or without the presence of miR-221/222. As shown in Fig. 3d, downregulation of E2F1 and Cyclin D1 was associated with upregulation of p27 by knockdown of miR-221/222 under normal cell culture condition. However, this kikd of regulation was not seen under starvation condition (Fig. 3e).

\section{Other miRNA-target interaction under regular and}

\section{starvation conditions}

In addition to miR-221/222, two more miRNAs with welldefined target gene and regulatory function in human breast cancer were selected to further confirm the influence of the miRNA-mRNA interaction by starvation. As shown in Fig. 4a and b, Cyclin D1 is a demonstrated target gene of miR-17-5p in MCF-7 breast cancer cells [28]. Cyclin D1 expression was significantly lower after transfection with miR-17-5p mimic in MCF-7 cells under normal condition (Fig. 4b). This effect was not observed in cells at starvation-induced stress status (Fig. 4b). Similar analysis was applied to confirmed the suppression of Socs 1 by miR-155 in MDA-MB-231 cells under regular culture condition [29], while starvation-induced stress condition completely attenuated this regulation (Fig. 4c-d). 


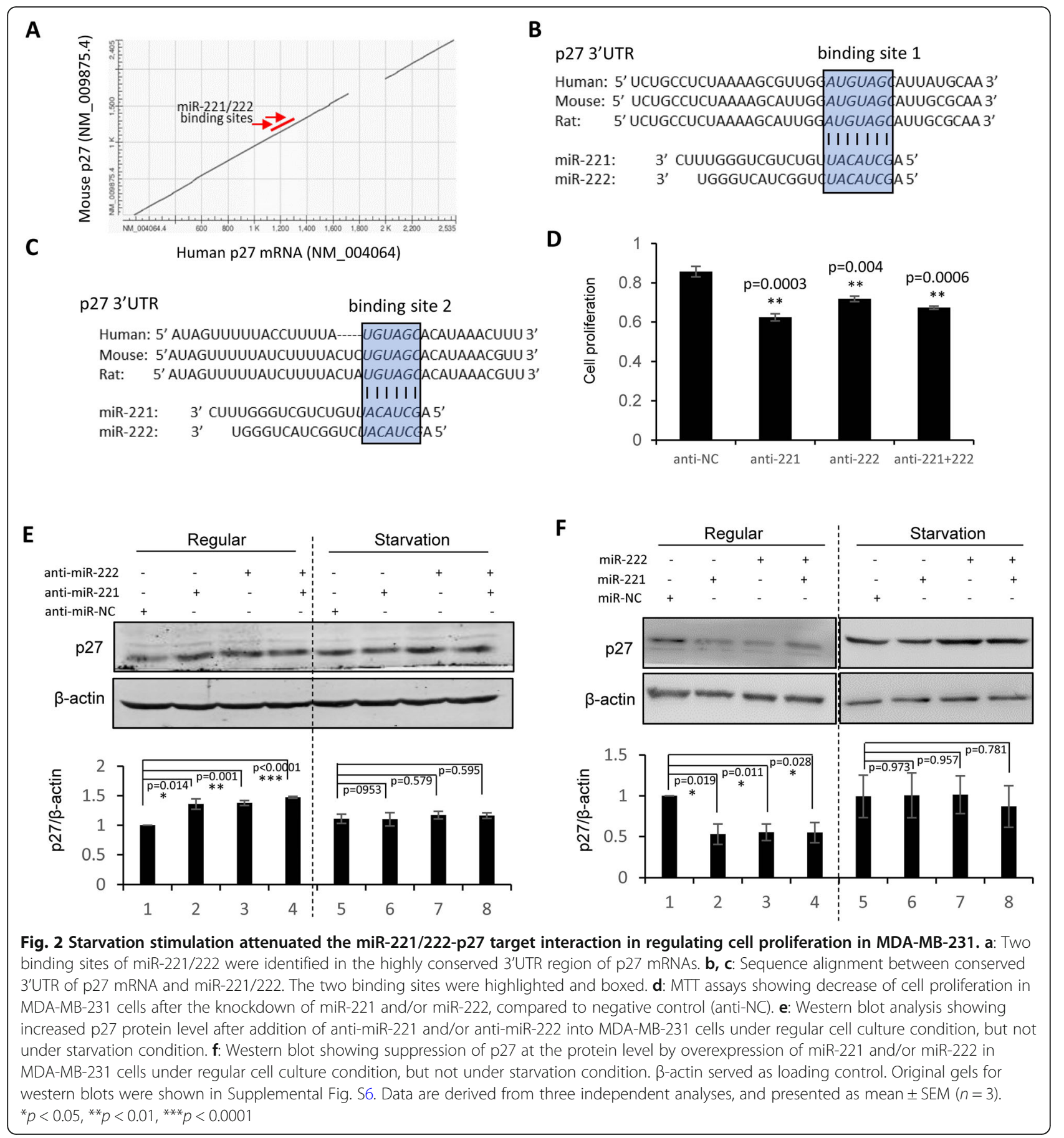

Decreased Ago2 expression was associated with attenuated miRNA-mRNA interaction under starvation condition

In order to determine the mechanisms through which miRNA-mRNA interaction is attenuated by starvation stimulation, Ago2 and Dicer1, two key components in the RNA-induced silencing complex (RISC) and regulating the target interaction between miRNAs and mRNAs, as well as Exportin 5 and Drosha, two factors regulating
miRNA biogenesis, were detected in MDA-MB-231 cells under regular and starvation conditions. As shown in Supplemental Fig. S4, Ago2 showed downregulation by starvation stimulation, while Dicer1, Drosha and Exportin did not. Western blot analyses were applied to further conform the downregulation of Ago2 by starvation stress (Fig. 5a). The attenuated regulation of p27 expression by anti-miR-221 and/or anti-miR-222 under starvation stimulation was rescued by addition of exogenous 


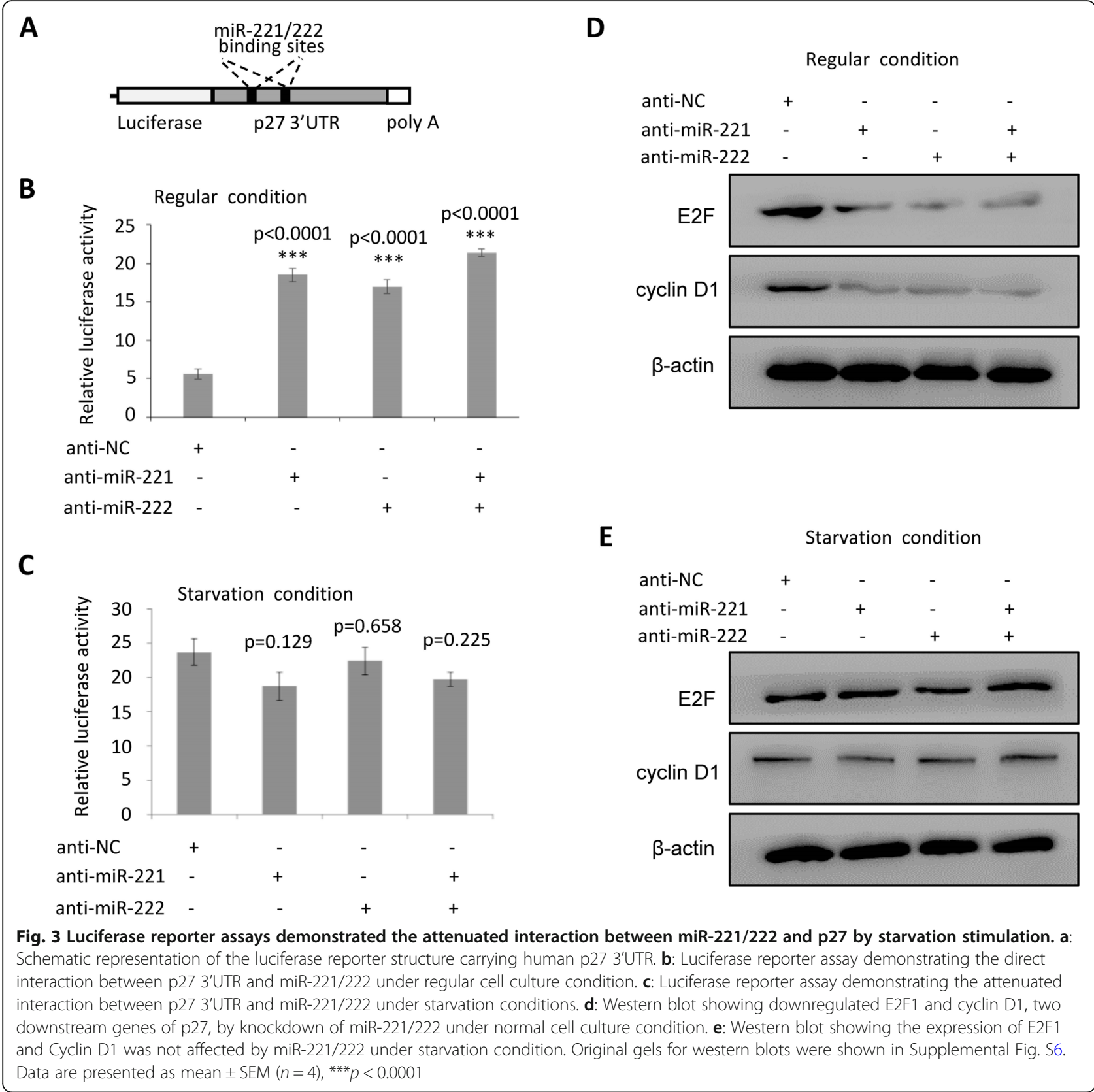

Ago2 into MDA-MB-231 cells (Supplemental Fig. S5, Fig. 5b). Targeted knockdown of Ago2 by siRNA treatment in MDA-MB-231 cells led to decreased cell proliferation (Fig. 5c). As such we hypothesized it is the downregulation of Ago2 by starvation that takes responsibility for the attenuated miR221/222-p27 interaction, leading to upregulation of p27 and the cell cycle arrest in MDA-MB-231 cells (Fig. 5d).

\section{Discussion}

In view of the lack of therapeutic target and poor 5-year survival for triple-negative breast cancer, novel forms of therapy are urgently needed. Limited access to nutritious supply is becoming a promising approach for suppressing tumor growth [14, 15]. In addition, miRNA-mRNAinteraction-targeted strategy could enhance the efficacy of chemo- and radio- therapy [30]. While beneficial reactions to fasting have been reported in animals, the underlying pathways have not been fully understood. Herein, we report that starvation suppresses cancer cell proliferation via attenuating miRNA-mRNA target interaction.

In the studied culture of MDA-MB-231 (triple-negative breast cancer cells), the content of miR-221/222 was high [26]. Under normal conditions, it inhibited the 


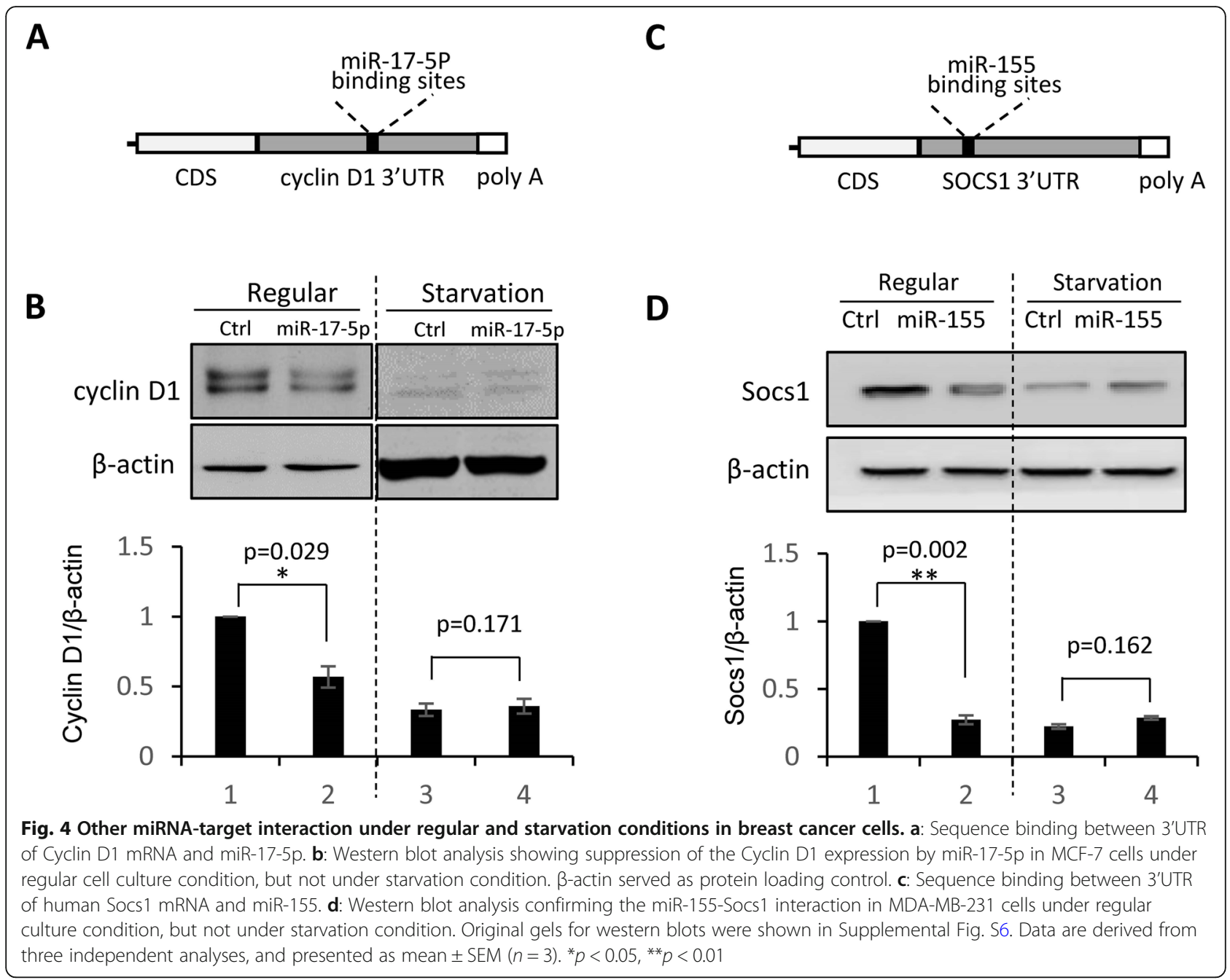

expression of p27 and promoted the proliferation and viability of cancer cells. Under starvation, miR-221/222 lost its inhibitory effect on p27 expression, which led to increase of the p27 level and inhibition of the cell cycle. The current study is the first to demonstrate the interruption of miRNA-mRNA interaction by starvation stimulation, which mediates suppression of cell proliferation in breast cancer. Furthermore, Ago2 was decreased under starvation condition, suggesting that RISC structure and function are inhibited in this specific cell status. As such, we propose that the starvation-induced downregulation of Ago2 attenuates the miR-221/222-p27 interaction, leading to a cell cycle arrest in MDA-MB-231 cells. These findings not only demonstrate a novel mechanism for starving cancer cells to inhibit tumor growth, but also add a new page to the general knowledge of the miRNA-mRNA target interaction. It suggests novel therapeutic targets: inhibition of mRNA-miRNA interaction via induced stress, could bring benefits to many breast cancer patients, especially those who lack any therapeutic target or cannot undergo full dose chemo- or radio- therapy.
In addition to miR-221/222-p27 interaction, other miRNA-mRNA interactions, such as miR-155-Socs1 and miR-17-5p-Cyclin D1, were also analyzed, and showed attenuation by starvation stimulation. Socs1, as a member of the suppressor of cytokine signaling family, inhibits Jak/Stat pathway and suppresses cytokine signal transduction. Socs1 is downregulated in breast cancer, functioning as a tumor suppressor [26]. Differing from Socs1, Cyclin D1 is overexpressed in more than $50 \%$ of breast cancer, encoding the regulatory subunit of a holoenzyme that phosphorylates the gene retinoblastoma (RB) and promotes G1/S cell cycle progression and oncogenesis [28]. The interrupted miRNA effects on the expression of target genes, such as oncogenes and/or tumor suppressors, should be a mechanism mediating the fasting-induced growth suppression of cancer cells.

In the current study, we demonstrated downregulation of Ago2, a key component of RISC, by starvation stimulation. In view of the similar mechanisms for miRNAs and siRNAs in regulating target gene expression through RISC, siRNA-mediated RNA interference 
A
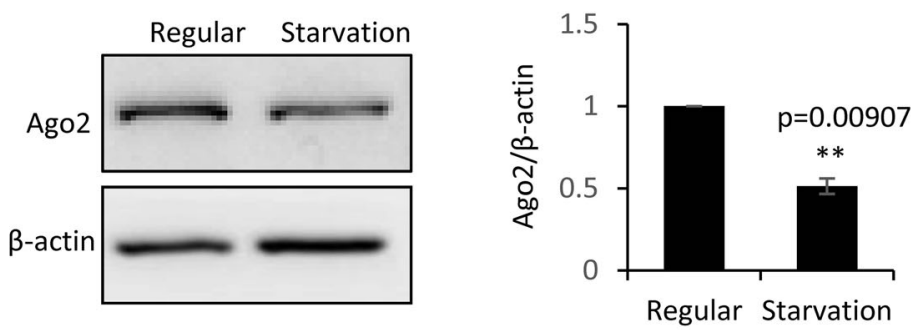

B

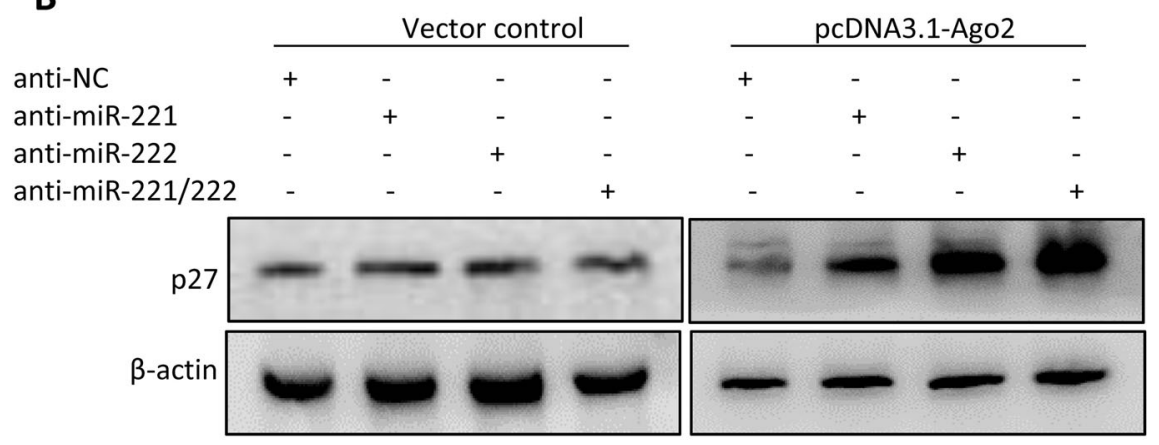

C

D
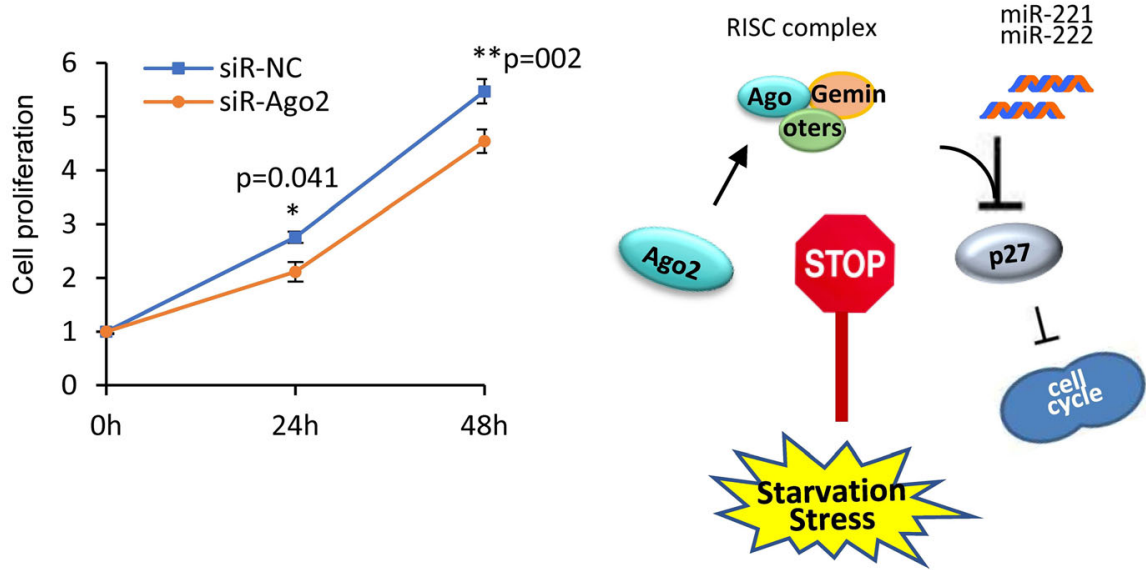

Fig. 5 Suppression of Ago2 expression by starvation stimulation. a: Western blot analysis demonstrating the inhibition of Ago2 expression by starvation stimulation in MDA-MB-231 cells. $\beta$-actin served as loading control. b: Western blot analysis demonstrating the attenuated regulation of p27 expression by anti-miR-221 and/or anti-miR-222 under starvation stimulation, which was rescued by addition of Ago2 using pcDNA-3.1-Ago2 plasmid. $\beta$-actin served as loading control. Original gels for western blots were shown in Supplemental Fig. S6. b: Cell proliferation assay showing decrease of cell proliferation in MDA-MB-231 cells after knockdown of Ago2 by siRNA. $\mathbf{d}$ : Schematic representation of mechanisms for regulating starvation-induced cell cycle arrest in human breast cancer cells. Downregulation of Ago2 by starvation attenuated the miR221/222-p27 interaction, leading to upregulation of p27 and cell cycle arrest in MDA-MB-231 cells. Data are derived from three independent analyses, and presented as mean $\pm \operatorname{SEM}(n=3) .{ }^{*} p<0.05,{ }^{* *} p<0.01$

(RNAi) effects on gene expression are very likely influenced in a starvation state. Although further experimental validation is required for the RNAi disruption by starvation stimulation, it remains unclear whether the RNAi strategy can be combined with the fasting strategy for cancer treatment. The implications of disturbed RNAi on the transcriptome in a starvation state have to be taken into account.

\section{Conclusion}

The current study demonstrated the attenuated interaction between miR-221/222 and p27 and decreased Ago2 expression by starvation-induced stress in MDA-MB-231 breast cancer cells. It adds a new page to the general knowledge of negative regulation of gene expression by miRNAs, also demonstrate a novel mechanism through which limited access to nutrients suppresses cancer cell proliferation. 


\section{Supplementary information}

Supplementary information accompanies this paper at https://doi.org/10. 1186/s12885-020-07118-3.

Additional file 1 Figure S1: MTT assays showing uninfluenced cell proliferation in MDA-MB-231 cells by knockdown of miR-221 and/or miR222 under starvation condition. Figure S2: Quantitative real-time PCR analysis showing increase of p27 expression at mRNA level by anti-miR221 and/or anti-miR-222 under regular cell culture condition, but not under starvation culture condition. Data are derived from three independent analyses, and presented as mean \pm SEM $(n=3)$. ${ }^{*} p<0.01$. Figure S3: Quantitative real-time PCR analysis showing suppressed expression of p27 at the mRNA levels in MDA-MB-231 cells by miR-221 and/or miR-222 overexpression under regular cell culture condition, but not under starvation condition. Data are derived from three independent analyses, and presented as mean $\pm \operatorname{SEM}(n=3) .{ }^{* *} p<0.01$. Figure S4: Quantitative real-time PCR analysis of the key factors regulating miRNA biogenesis and function, including Exportin 5, Dicer 1, Ago2 and Drosha in MDA-MB-231 cells under regular and starvation culture conditions. Data are derived from three independent analyses, and presented as mean $\pm \operatorname{SEM}(n=3) .{ }^{* *} p<0.01$. Figure S5: Western blot analysis demonstrating the overexpression of Ago2 in MDA-MB-231 cells transfected with pcDNA 3.1-Ago2 plasmid. Empty vector was used as negative control. $\beta$ actin served as loading control. Figure S6: Original gels for all western blots in Figures.

\section{Abbreviations}

miRNA: microRNA; RISC: RNA-induced silencing complex; ER: Estrogen receptor; PR: Progesterone receptor; NCD: Neurocognitive disorders; FBS: Fetal bovine serum; RNAi: RNA interference; RB: Retinoblastoma

\section{Acknowledgements}

Not applicable.

\section{Authors' contributions}

$Z Y$ and EB designed the research and wrote the paper. $J L, C Z, Z X, J H, Y L, L Z$, YG and ZW performed experiments. QZ did data analysis. All authors have read and approved the manuscript.

\section{Funding}

This work was supported by grants 81772810 and 81972476 from the National Natural Science Foundation of China (materials purchase and manuscript preparation), and grant from the Top-level Clinical Discipline Project of Shanghai Pudong PWYgf 2018-05 (materials sharing). Evelyne Bischof (Ewelina Biskup) was supported by Krebsliga Schweiz, BIL KFS 4261-08-2017.

\section{Availability of data and materials}

Data sharing is not applicable to this article as no datasets were generated or analyzed during the current study.

\section{Ethics approval and consent to participate}

Neither human specimens nor animals were used in this study. The two cell lines used in the article do not require ethics approval.

\section{Consent for publication}

Not applicable.

\section{Competing interests}

There are no conflicts of interest associated with this manuscript.

\section{Author details}

${ }^{1}$ Research Center for Translational Medicine, Tongji University School of Medicine, 150 Jimo Road, Shanghai 200120, China. Department of Surgery, Shanghai East Hospital, Tongji University School of Medicine, 150 Jimo Road, Shanghai 200120, China. ${ }^{3}$ Jinzhou Medical University, Liaoning, China. ${ }^{4}$ Shanghai University of Medicine and Health Sciences Clinical Medicine Division, Shanghai, China. ${ }^{5}$ Division of Internal Medicine, University Hospital of Basel, Petersgraben 4, 4051 Basel I, Switzerland.
Received: 17 October 2019 Accepted: 26 June 2020

Published online: 06 July 2020

\section{References}

1. Le Saux O, Ripamonti B, Bruyas A, Bonin O, Freyer G, Bonnefoy M, et al. Optimal management of breast cancer in the elderly patient: current perspectives. Clin Interv Aging. 2015;10:157-74.

2. Gusterson BA, Stein T. Human breast development. Semin Cell Dev Biol. 2012;23(5):567-73.

3. Ferlay J, Colombet M, Soerjomataram I, Dyba T, Randi G, Bettio M, et al. Cancer incidence and mortality patterns in Europe: estimates for 40 countries and 25 major cancers in 2018. Eur J Cancer. 2018;103:356-87.

4. Payne SJ, Bowen RL, Jones JL, Wells CA. Predictive markers in breast cancer--the present. Histopathology. 2008;52(1):82-90.

5. Millar EK, Graham PH, McNeil CM, Browne L, O'Toole SA, Boulghourjian A, et al. Prediction of outcome of early ER+ breast cancer is improved using a biomarker panel, which includes Ki-67 and p53. Br J Cancer. 2011;105(2): 272-80

6. Cai FF, Xu C, Pan X, Cai L, Lin XY, Chen S, et al. Prognostic value of plasma levels of HIF-1a and PGC-1a in breast cancer. Oncotarget. 2016;7(47):77793806.

7. Lin XY, Cai FF, Wang MH, Pan X, Wang F, Cai L, et al. Mammalian sterile 20like kinase 1 expression and its prognostic significance in patients with breast cancer. Oncol Lett. 2017;14(5):5457-63.

8. Parks RM, Cheung KL. Personalising Care in the Older Woman with primary breast Cancer. Ann Acad Med Singap. 2019:48(11):370-5.

9. Andersen SL, Terry DF, Wilcox MA, Babineau T, Malek K, Perls TT. Cancer in the oldest old. Mech Ageing Dev. 2005;126(2):263-7.

10. Lichtman SM. Guidelines for the treatment of elderly cancer patients. Cancer Control. 2003:10(6):445-53.

11. Baird RD, Caldas C. Genetic heterogeneity in breast cancer: the road to personalized medicine? BMC Med. 2013;11:151.

12. Sabatier R, Goncalves A, Bertucci F. Personalized medicine: present and future of breast cancer management. Crit Rev Oncol Hematol. 2014;91(3): 223-33.

13. Dawson SJ, Rueda OM, Aparicio S, Caldas C. A new genome-driven integrated classification of breast cancer and its implications. EMBO J. 2013; 32(5):617-28.

14. Wokoun U, Hellriegel M, Emons G, Grundker C. Co-treatment of breast cancer cells with pharmacologic doses of 2-deoxy-D-glucose and metformin: starving tumors. Oncol Rep. 2017;37(4):2418-24.

15. Selwan EM, Finicle BT, Kim SM, Edinger AL. Attacking the supply wagons to starve cancer cells to death. FEBS Lett. 2016;590(7):885-907.

16. Mukherjee P, El-Abbadi MM, Kasperzyk JL, Ranes MK, Seyfried TN. Dietary restriction reduces angiogenesis and growth in an orthotopic mouse brain tumour model. Br J Cancer. 2002;86(10):1615-21.

17. Maddocks ODK, Athineos D, Cheung EC, Lee P, Zhang T, van den Broek NJF, et al. Modulating the therapeutic response of tumours to dietary serine and glycine starvation. Nature. 2017;544(7650):372-6.

18. Lee C, Raffaghello L, Brandhorst S, Safdie FM, Bianchi G, Martin-Montalvo A, et al. Fasting cycles retard growth of tumors and sensitize a range of cancer cell types to chemotherapy. Sci Transl Med. 2012;4(124):124ra127.

19. Raffaghello L, Lee C, Safdie FM, Wei M, Madia F, Bianchi G, et al. Starvationdependent differential stress resistance protects normal but not cancer cells against high-dose chemotherapy. Proc Natl Acad Sci U S A. 2008;105(24): 8215-20.

20. Swanton C, Burrell RA, Futreal PA. Breast cancer genome heterogeneity: a challenge to personalised medicine? Breast Cancer Res. 2011;13(1):104.

21. Burrell RA, McClelland SE, Endesfelder D, Groth P, Weller MC, Shaikh N, et al. Replication stress links structural and numerical cancer chromosomal instability. Nature. 2013;494(7438):492-6.

22. Li Z, Peng Z, Gu S, Zheng J, Feng D, Qin Q, et al. Global analysis of miRNAmRNA interaction network in breast Cancer with brain metastasis. Anticancer Res. 2017;37(8):4455-68.

23. Lee $\mathrm{S}$, Jiang $\mathrm{X}$. Modeling miRNA-mRNA interactions that cause phenotypic abnormality in breast cancer patients. PLoS One. 2017:12(8):e0182666.

24. Vasudevan S, Tong Y, Steitz JA. Switching from repression to activation: microRNAs can up-regulate translation. Science. 2007:318(5858):1931-4.

25. Valinezhad Orang A, Safaralizadeh R, Kazemzadeh-Bavili M. Mechanisms of miRNA-mediated gene regulation from common Downregulation to mRNA-specific Upregulation. Int J Genomics. 2014;2014:970607. 
26. Li Y, Liang C, Ma H, Zhao Q, Lu Y, Xiang Z, et al. miR-221/222 promotes Sphase entry and cellular migration in control of basal-like breast cancer. Molecules. 2014;19(6):7122-37.

27. Zhao JJ, Lin J, Yang H, Kong W, He L, Ma X, et al. MicroRNA-221/222 negatively regulates estrogen receptor alpha and is associated with tamoxifen resistance in breast cancer. J Biol Chem. 2008;283(45):31079-86.

28. Yu Z, Wang C, Wang M, Li Z, Casimiro MC, Liu M, et al. A cyclin D1/ microRNA 17/20 regulatory feedback loop in control of breast cancer cell proliferation. J Cell Biol. 2008;182(3):509-17.

29. Jiang $\mathrm{S}$, Zhang HW, Lu MH, He XH, Li Y, Gu H, et al. MicroRNA-155 functions as an OncomiR in breast cancer by targeting the suppressor of cytokine signaling 1 gene. Cancer Res. 2010;70(8):3119-27.

30. Miller TE, Ghoshal K, Ramaswamy B, Roy S, Datta J, Shapiro CL, et al. MicroRNA-221/222 confers tamoxifen resistance in breast cancer by targeting p27Kip1. J Biol Chem. 2008;283(44):29897-903.

\section{Publisher's Note}

Springer Nature remains neutral with regard to jurisdictional claims in published maps and institutional affiliations.

Ready to submit your research? Choose BMC and benefit from:

- fast, convenient online submission

- thorough peer review by experienced researchers in your field

- rapid publication on acceptance

- support for research data, including large and complex data types

- gold Open Access which fosters wider collaboration and increased citations

- maximum visibility for your research: over $100 \mathrm{M}$ website views per year

At BMC, research is always in progress.

Learn more biomedcentral.com/submissions 